\title{
A LITERATURA DE CÁRCERE EM DEFESA DE UM CONDENADO À PENA DE MORTE NO JAPÃO - LÁGRIMAS DA IGNORÂNCIA, DE NORIO NAGAYAMA
}

\author{
LILIAN YAMAMOTO 1
}

\begin{abstract}
RESUMO: Apesar de o Japão da década de 1960 ter passado por uma fase de crescimento econômico acelerado, ainda restavam rincões de pobreza em várias regiões do país. Condenado à morte, Norio Nagayama, de origem humilde, é exemplo de criminoso influenciado por tal contexto. Nagayama foi autodidata no seu período de cárcere e logrou êxito na sua carreira literária, que culminou com o recebimento do prêmio japonês de Nova Literatura em 1983. Tendo sido preso após cometer quatro homicídios em 1968, seu caso constituiu um novo marco para o estabelecimento de critérios para a condenação à pena de morte no Japão. O presente artigo pretende analisar a influência da sua primeira obra, Muchi no Namida (Lágrimas da ignorância, 1971), na sua defesa apresentada nos tribunais. Essa obra é uma coletânea de seus cadernos de anotações de poesia e prosa com referência direta a eventos da sua infância e adolescência, a ideias sobre justiça social e, sobretudo, à sua viagem interna em busca da motivação de seus crimes. Assim, um exame sobre a persistência da pena de morte no sistema penal japonês se mostra de fundamental importância para maior entendimento do contexto em que o autor viveu.
\end{abstract}

PalaVRas-chave: pena de morte no Japão; literatura de cárcere; defesa.

\section{INTRODUÇÃO}

Norio Nagayama nasceu em uma família humilde, tinha sete irmãos e seu pai era um viciado em apostas. A mãe o abandonou em Abashiri com os seus irmãos mais velhos, na província de Hokkaido, na tentativa de sustentar o resto da prole em Aomori. Apesar da infância e do início da vida adulta atribulados, Norio Nagayama conseguiu se tornar um escritor

1 Doutora em Direito Internacional pela Universidade Kanagawa (Japão). Pós-doutoranda do Programa de Pós-Graduação em Língua, Literatura e Cultura Japonesa da Faculdade de Filosofia, Letras e Ciências Humanas da Universidade de São Paulo - USP (Brasil). São Paulo, SP, Brasil. E-mail: lilianmitsuko@yahoo.it 
premiado e de grande vendagem durante o seu período no cárcere (Otani, 2010, p. 34). Nascido em Abashiri, Japão, em 1949, Norio inicialmente tornou-se conhecido pela série de quatro homicídios praticados entre 11 de outubro e 5 de novembro de 1968, cujas vítimas foram dois vigias e dois motoristas de táxi, mortos em cidades diversas (Ishikawa, 2013, p. 5).

Os crimes atraíram a atenção do país para os problemas sociais no Japão, durante o período do crescimento econômico, e suas repercussões foram de tal tamanho que constituíram um novo marco para o estabelecimento de critérios para a condenação à morte no país. Quando a sociedade japonesa estava emergindo do período pós-guerra, um grande número de jovens de origem humilde e com apenas o ensino médio, como Nagayama, saíram de seus lares para trabalhar em Tóquio e em outras capitais promissoras, tendo sido apelidados de "ovos de ouro".

A miséria e a falta de perspectivas são o cenário de sua primeira obra, Muchi no Namida (Lágrimas da ignorância, 1971), na qual o autor procura justificar os motivos da sua delinquência, e poesia e prosa se mesclam em textos esparsos cuja temática gira em torno da busca de motivação para os seus crimes. A mesma argumentação do livro é utilizada durante as sessões no tribunal que ele enfrenta durante muitos anos. O olhar é dirigido ao seu passado miserável, como se o seu livre-arbítrio fosse seriamente comprometido pelas experiências traumáticas vivenciadas antes do cometimento dos crimes. Nagayama foi autor de nove obras², das quais uma foi premiada: ele recebeu o Shin Nihon Bungakusho (Prêmio da Nova Literatura) em 1983, pela obra Kibashi (Ponte de madeira), publicada no ano seguinte. $\mathrm{O}$ faturamento das vendas dos seus livros foi doado para os familiares das vítimas e para organizações de caridade no Perus. Nagayama foi executado em 1997, aos 48 anos de idade, após passar por inúmeras tentativas de pedido de clemência.

\footnotetext{
2 Muchi no Namida (Lágrimas da ignorância, 1971), Ai ka Mu kA (O amor ou nada, 1973), Kibashi (Ponte de madeira, 1984), Soren no Tabigeinin (A União Soviética do artistaviajante, 1986), Sutego Gokko (A criança abandonada, 1987), Shikeino Namida (Lágrimas da pena de morte, 1988), Nazeka Umi (Não sei porque o mar, 1989), Isui (Outras águas, 1990), Hana (Flor, 1997).

3 Nagayama escolheu as crianças do Peru por causa de uma reportagem de 1997, do jornal Asahi, que mencionava o trabalho infantil no país, sob o título "Os pequenos trabalhadores que se empenham”. Os direitos autorais foram doados para Manthoc, uma ONG criada em 1976 e que promove os direitos humanos das crianças nas comunidades carentes andinas.
} 
Neste artigo, pretende-se analisar a vida e a obra de Norio na prisão e a sua visão de responsabilidade penal, discorrida em seu primeiro livro. Além disso, investigaremos a influência da sua obra na sua defesa apresentada nos tribunais. Assim, um exame sobre a persistência da pena de morte no sistema penal japonês se mostra de fundamental importância para o maior entendimento do contexto do autor.

Trata-se de uma pesquisa desenvolvida a partir da leitura da fonte primária, Muchi no Namida (Lágrimas da ignorância, 1971), e de revisão bibliográfica de artigos e livros relacionados à pena de morte no Japão e à vida e obra de Nagayama.

\section{A OBRA DE NAGAYAMA \\ E O DIREITO A PARTIR DA LITERATURA}

O gênero literário japonês denominado Watakushi Shôsetsu pode ser traduzido como "narrativa do eu" e teve origem nas primeiras décadas do séc. XX. Havia certa preocupação por parte dos estudiosos japoneses com a falta de estruturação do romance e da ausência de criação do personagem principal, o que poderia ocasionar a destruição do desenvolvimento literário japonês (Nagae, 2006, p. 4). A obra de Nagayama pertence a tal gênero literário e, na sua obra Muchi no Namida, o narrador é também o protagonista.

Uma vez que Nagayama teve uma dura experiência com a realidade da aplicação da pena de morte no Japão, faz-se necessária a análise da conexão entre a sua obra literária e o sistema penal japonês. O constante contato com advogados e o cotidiano na prisão influenciaram a sua obra, mas ele não faz referência direta ao julgamento, optando por tentar descobrir o que poderia ter ocasionado a sua relação de ódio com a sociedade.

Para melhor entendermos a ligação de sua obra com o Direito, convém analisar os primórdios dos estudos de Direito e Literatura, que remontam ao século XIX, com artigos de autoria de advogados ingleses, cujo conteúdo descrevia o sistema jurídico nas obras de Dickens, Shakespeare e outros. Entretanto, apenas em 1973, através da obra de James Boyd White, The Legal Imagination, é que o campo do Direito e Literatura tornou-se autônomo. Até então, a área de conhecimento 
consistia em lembretes de que o Direito era um tema frequente na Literatura e que as opiniões jurídicas teriam uma característica literária (Posner, 1986, p. 1392). O estudo de Direito e Literatura se divide de maneira geral em duas grandes modalidades: "Direito a partir da Literatura" e "Direito como Literatura". Naquele, o ordenamento jurídico e toda a sua operacionalização são representados no mundo literário exemplos desse enfoque são vistos em obras clássicas como Antígona de Sófocles, Crime e castigo de Dostoiévski, O processo de Kafka, dentre outros. O "Direito como Literatura", por sua vez, é aplicado em todos os tipos de leis e nos seus casos, e seu valor para a sociedade pode ser discutido, permitindo que se pense profundamente sobre os seres humanos e suas comunidades (Chang, 2008, p. 68-69). A interpretação seria uma interferência na prática jurídica, a exemplo dos estudos sobre a descoberta dos significados dos textos (Godoy, 2003, p. 133).

O estudo da obra de Nagayama seria um representante da categoria "Direito a partir da Literatura", uma vez que as suas obras apontam a delinquência como fruto da desigualdade social. O Direito é representado em face das condições que fizeram aflorar a sua criminalidade, toca na persistência do sistema penal japonês em manter a pena de morte (uma vez que Nagayama foi o símbolo dos opositores à pena de morte no Japão), e na Literatura é representada pela narrativa que trabalha em sua defesa, que intencionava ganhar a simpatia da opinião pública com Muchi no Namida (Lágrimas da ignorância, 1971). Essa obra foi o primeiro passo para que o autor criasse seu próprio mundo narrativo, tendo proporcionado a Nagayama os meios para que tivesse controle total para evocar seus fantasmas e buscar as causas dos seus crimes. Nota-se que a obra literária, ao contrário da obra jurídica, é uma obra de arte que pode romper com convenções, não tendo compromisso com a realidade, sendo direcionada ao leitor comum (Trindade, 2012, p. 3). Sua ficção, entretanto, não se opõe à realidade, e suas obras mesclam as suas memórias do período fora do cárcere com seus sonhos de uma sociedade ideal na qual a criminalidade não existiria.

Nagayama narra, assim, a própria versão dos fatos no romance $M u c h i$ no Namida e denuncia o sistema penal como um ordenamento imperfeito, que julga apenas os delitos pelas suas causas imediatas e ignora as 
motivações, que seriam as verdadeiras raízes da criminalidade. Assim, as obras literárias de Nagayama conseguem empatia do leitor com a sua situação, possibilitando vê-lo integralmente como um ser humano (Tamagnone e Oliveira, 2013, p. 35).

Ademais, a sua obra tem servido como fonte inesgotável de inspiração para discussões a respeito da regeneração dos presos, uma vez que ele próprio estudou e se tornou um escritor após a sua condenação, com o desenvolvimento do seu espírito solidário e consciência crítica. Sua vida e obra são uma fonte de inspiração para os trabalhos das ONGs que lutam pela abolição da pena de morte e por melhorias nas condições de vida nos centros de detenção.

A sua defesa na obra Muchi no Namida lhe deu resultados favoráveis, na medida em que a decisão da Suprema Corte de Tóquio comutou a sua pena de morte para a perpétua em 1981: "O governo deveria ter poupado o réu da pobreza e seria injusto ignorar a ausência de políticas apropriadas que visassem o bem-estar da população, responsabilizando-o por tudo" (Obara, 2013, p. 32). Apesar do reconhecimento, por parte da justiça, da influência do contexto miserável em que Nagayama vivia e de tal contexto ter sido um dos gatilhos para a sua delinquência, a decisão das autoridades foi novamente revertida, e ele foi executado em 1997.

\section{A PENA DE MORTE NO JAPÃO E O PROCESSO DE NAGAYAMA}

O Japão é um dos poucos países desenvolvidos em que a pena de morte ainda existe no ordenamento jurídico. Apesar de o país ainda mantêlas, nota-se uma diminuição visível no número de execuções nos últimos anos. O Japão ratificou o Pacto de Direitos Civis e Políticos (1966) em 1979,

\footnotetext{
4 Anistia Internacional, Center for Prisoners Rights, International Federation for Human Rights, among others.

5 Outros países que, em outubro de 2015, mantêm a pena de morte são: Afeganistão, Antigua e Barbuda, Bahamas, Bahrain, Bangladesh, Barbados, Bielarússia, Belize, Botswana, Chad, China, Comoros, República Democrática do Congo, Cuba, Dominica, Egito, Guiné Equatorial, Etiópia, Gâmbia, Guatemala, Guiné, Guiana, India, Indonésia, Irã, Iraque, Jamaica, Japão, Jordânia, Kuweit, Líbano, Lesoto, Líbia, Malásia, Nigéria,Coréia do Norte, Omã, Paquistão, Palestina, Catar, São Cristóvão e Nevis, Santa Lucia, São Vicente e Grenadinas, Arábia Saudita, Cingapura, Somália, Sudão do Sul, Sudão, Síria, Taiwan, Tailândia, Trinidade e Tobago, Uganda, Emirados Árabes Unidos, Estados Unidos, Vietnã, Yemen, Zimbábue.
} 
sem reservas. Apesar desse instrumento, no seu art. 6(2), não vetar explicitamente a pena de morte, estipula que, nos países que não a aboliram, a sua aplicação deverá ser feita para "os crimes mais graves", além de prever critérios para a proteção de privação do direito à vida art.6(1) -, através de tribunais competentes, previsão de procedimentos de apelação e tratamento humano dos condenados. Entretanto, o art.6(6) prevê que "Não poderá ser invocada nenhuma disposição do presente artigo para retardar ou impedir a abolição da pena de morte por um Estado que parte do presente Pacto”. O Japão, no entanto, não ratificou o instrumento com vistas à Abolição da Pena de Morte, tampouco o Segundo Protocolo Facultativo ao Pacto Internacional sobre Direitos Civis e Políticos, o que demonstra o seu posicionamento claro de manutenção de tal pena.

O Código Penal em vigência (1908) prevê que o modo de execução ocorra exclusivamente por enforcamento (art. 11), forma pela qual o autor Norio Nagayama foi executado em 1997. Atualmente, existem diversos crimes $^{6}$ que podem incidir na pena de morte, mas, em especial, as

6 Os crimes que implicam em pena de morte são homicídio: Matar outra pessoa é crime punível com pena de morte. Contudo, em termos práticos, o Japão somente impõe pena de morte se o homicídio estiver acompanhado de fatores agravantes, incluindo várias vítimas e o cometimento de outros crimes (Código Penal, art. 199). Outros crimes que resultam em morte: O roubo seguido de morte (latrocínio) na cena do crime do roubo é punível com pena de morte (Código Penal, art. 240); O estupro concomitante ao roubo que cause morte é punível com pena de morte (Código Penal, art. 241); A poluição de água potável pública que cause a morte de uma pessoa é punível com pena de morte (Código Penal, art. 146); Causar a morte de uma pessoa no cometimento de um capotamento ou destruição de trem ou bonde ou durante a virada de embarcação (emborcamento) que cause a morte de uma pessoa é punível com pena de morte (Código Penal, art. 126); A direção perigosa, que leve ao capotamento de trem ou bonde ou virar embarcação (emborcamento) que cause a morte de outra pessoa é punível com pena de morte (Código Penal, arts. 125-127); Participar de um duelo que cause morte também é punível com a morte. Lei Especial: Crimes relacionados ao terrorismo que resultem em morte; Sequestrar um avião que cause a morte e destruição de aeronaves que resulte em morte são puníveis com pena de morte; Crimes relacionados ao terrorismo que não resultem em morte; Destruição por explosivos e uso ilegal de explosivos são condutas puníveis com pena de morte (Código Penal, art. 117); Incêndio que não resulte em morte (Código Penal, art. 108); Incendiar um edifício, trem, bonde, embarcação ou mina em que uma pessoa esteja, ou que seja usada como moradia é conduta punível com pena de morte (Código Penal, art. 108); Traição (Código Penal, arts. 81, 82, 77(1)-i); Instigar agressão estrangeira (Código Penal, art. 81) contra o Japão também acarreta pena de morte. Auxiliar um inimigo por meio de serviço militar direto ou que, de alguma forma, permita vantagem militar é punível com pena de morte (Código Penal, art. 82). Liderar insurreição é conduta punível com pena de morte (Código Penal, art. 77(1)-i); Outros crimes que não resultem em morte; Os crimes a seguir são puníveis com a morte: Dar causa à inundação que danifique um edifício, trem, bonde ou mina que seja usada como moradia ou onde pessoas estejam presentes é punível com morte (Código Penal, art. 119); Detonar explosivo e que, assim, danifique edifício, trem, bonde, embarcação ou mina que seja utilizada como moradia ou onde outras pessoas 
condenações ocorrem quando há a morte da vítima. Esse código ainda está em vigência, tendo o caso Nagayama estabelecido novos critérios de condenação à morte, atualmente aplicados nos julgamentos que podem incidir na pena de morte. Nesse caso, os seguintes fatores são analisados:

1) a natureza do homicídio;

2) a motivação;

3) o método empregado no homicídio;

4) o número de pessoas mortas;

5) o sentimento dos familiares da vítima;

6) a magnitude das implicações sociais do caso;

7) a idade do réu;

8) os precedentes criminais do réu e;

9) demonstração de remorso pelo réu (Otani, 2010, p. 200).

As execuções são feitas mediante a autorização do Ministro da Justiça (art. 475 do Código de Processo Penal), que deve decidir o número de execuções e indicar os condenados que serão executados (The International Federation for Human Rights, 2003, p. 10). Uma vez que o Ministro da Justiça ordena a execução da pena de morte, ela deverá ser realizada no prazo de 5 dias. O art. 475 do CPP requer a ordem do Ministro da Justiça para a sentença ser executada, e, se o Ministro optar por não executar a ordem, ela será suspensa. Entre 1989 e 1993, houve moratória nas execuções porque os Ministros da Justiça que atuaram durante esse período tinham posicionamento contrário à pena.

Entre a decisão da corte distrital de Tóquio e da Suprema Corte, o processo de Nagayama estendeu-se por onze anos, e durante esse período a sua condenação à morte foi comutada para pena perpétua e novamente revertida em pena de morte. Apesar de ter passado a maior parte da vida na

estejam presentes é punível com morte (Código Penal, arts. 108, 117-1); Causar dano em estrutura não habitada por violação de domicílio (Código Penal, art. 119). Disponível em: <http://www.deathpenaltyworldwide.org/country-search-post.cfm?country=Japan>. Acesso em: 2 out. 2015.

7 JAPÃO. Corte Distrital de Tóquio. Condenação à morte, Tóquio, 10 de julho de 1979; O Tribunal Superior de Tóquio comutou a pena de morte para pena perpétua, Tóquio, 21 de agosto de 1981; A Suprema Corte Japonesa reformou o julgado do TST e devolveu o caso para o TST, Tóquio, 8 de julho de 1983; O TST reformou o julgado para a pena de morte, 
prisão, Nagayama casou-se com Kazumi, em 1981. A esposa de Norio era filha de mãe japonesa e pai americano, nasceu em 1955 e viveu na base militar em Okinawa, tendo se mudado, posteriormente, para os EUA. O seu interesse por Nagayama surgiu após fazer repetidas leituras da obra Muchi no Namida.

A execução ocorreu em $1^{\circ}$ de agosto de 1997, e os advogados de Nagayama foram informados de sua morte apenas dois dias após. A data escolhida foi próxima de outro caso que havia causado comoção popular. Naquele ano, diversos crimes foram cometidos por menores de idade, como o caso de Sakakihara, em que o suspeito foi preso no dia 28 de junho de 1997 (Otani, 2010, p. 162). Na ocasião de sua morte, a Anistia Internacional emitiu a seguinte nota:

Quatro pessoas foram enforcadas em segredo no dia 10 de agosto, incluindo o conhecido escritor Norio Nagayama, que esteve na prisão por 28 anos. Os quatro prisioneiros, todos condenados por homicídio, parecem ter sido selecionados ao acaso dentre 55 prisioneiros cujas sentenças de morte foram finalizadas. Como normalmente ocorre no Japão, eles e as suas famílias não foram previamente avisados acerca das execuções. Havia uma mulher dentre os quatro (The New York Times, 1997).

As organizações que lutam pela abo1ição da pena de morte indicam que os condenados passam, em média, mais de três décadas esperando pela execução. A data da execução não é notificada para o condenado, tampouco para seus familiares, e, como os condenados enfrentam a angústia diária de não saberem quando serão executados, muitos desenvolvem transtornos mentais.

O governo tem se baseado em pesquisas de opinião pública, obtendo altos índices de aprovação da pena de morte, em torno de 85.5\% em 2009 (Obara, 2013, p. 60). Autores como Sato (2013, p.3 4) destacam que a abolição não ocorre devido à falta de vontade política da elite burocrática do país, que adota perspectivas preventivas, bem como deontológica, do sistema penal. $\mathrm{O}$ caráter preventivo caracteriza-se pelo fato de a pena ser cruel o suficiente para o indivíduo ser levado a realizar o cálculo utilitário

Tóquio, 18 de março de 1987; 17/04/1990 - A Suprema Corte Japonesa manteve a decisão da pena de morte, Tóquio, 17 de abril de 1990. 
que o faça abster-se do ato criminoso. Assim, a pena de morte viria a coibir a criminalidade. Da mesma forma, a severidade da pena tem como objetivo causar temor e prevenir que o criminoso seja libertado e venha a tornar-se reincidente (Geis, 1955-56, p. 166). Nessa perspectiva, a vida do criminoso é sacrificada para a salvação dos demais indivíduos da sociedade.

A deontologia, por sua vez, valoriza o conceito de dever para só depois considerar as consequências das ações. Tem como um dos maiores representantes Immanuel Kant, que argumenta que a punição deve ser a resposta para a culpa. Ela deve ocorrer de maneira que a justiça e a igualdade possam existir. Kant também defende a igualdade nos domínios do crime e da punição: o criminoso deverá suportar o mesmo montante de dor que o imputado à vítima. Como ninguém força uma pessoa a cometer crimes, se ela o faz, deve estar desejando receber o mesmo tipo de tratamento; apesar de se retribuir do mesmo modo que a ação, não se considera uma forma de vingança (Potter, 1998, p. 173). Desse modo, o governo japonês tem defendido a manutenção da pena utilizando-se também de tais teorias.

\section{MUCHI NO NAMIDA (LÁGRIMAS DA IGNORÂNCIA, 1971)}

Nagayama concluiu apenas o ensino fundamental, mas, após entrar no cárcere, tornou-se um ávido leitor de psicologia, de filosofia e de autores como Dostoiévski, Chekov, Marx, dentre outros. A capacidade de se expressar progrediu de tal forma que o juiz associado à Corte Distrital de Tóquio, Akira Toyoshi, quem condenou Nagayama à morte, afirmou que durante as sessões do julgamento começou a perceber mudanças consideráveis no réu. Se, no início, desconhecia muitas matérias, veio a aperfeiçoar-se por meio da leitura e pesquisa de filosofia e literatura: "Honestamente, houve mais de uma ocasião em que, antes da minha decisão, fiquei em dúvida se o réu deveria ser sentenciado à morte. Acredito que a Suprema Corte tenha feito uma feliz escolha ao criar o critério de 9 fatores para a aplicação da pena de morte” (Métraux, 2009, p. 287).

No início, durante as audiências, Nagayama permanecia calado a maior parte do tempo, não conversando sequer com seus advogados (Otani, 2010, p. 40). Essa ausência de plenitude da manifestação expressiva deviase ao seu processo inverso de aprendizado da linguagem. Em geral, a 
criança aprende primeiro a linguagem falada no seio familiar para depois progredir na escrita, através da leitura incentivada pela escola. Assim, o aprendizado deriva de um processo de imitação e repetição para, de modo quase misterioso, a criança desenvolver a capacidade peculiar de se expressar (Hosomi, 2010, p. 140).

Nagayama, porém, foi abandonado pela mãe durante a infância e recebeu maus-tratos dos irmãos, com os quais mal conversava, tendo tido assim um aprendizado de linguagem comprometido, mas cuja deficiência ele buscou sanar no cárcere, onde se dedicou de forma fervorosa aos estudos. Essa ânsia para superar a ignorância é perceptível no uso peculiar da linguagem escrita; por exemplo, ele exagera no emprego de kanjis $^{8}$, quando a palavra deveria ser escrita em hiragana. ${ }^{\circ}$ Após sua prisão, ao perder a liberdade e, confinado na cela, pela primeira vez teve de se confrontar consigo mesmo. Como não tinha domínio da linguagem, dedicou-se ao aprendizado de palavras que aumentassem o seu vocabulário, estudando e memorizando-as a partir do dicionário para, então, reescrever os kanjis. Desse modo, ele tenta escapar da sua condição miserável através do desenvolvimento intelectual e, nesse processo cognitivo, passa a sonhar com uma transformação social.

As anotações dos seus rascunhos deixam claro que ele treinava seriamente a escrita de kanjis, de modo que o estudo de vocabulário foi desenvolvido a um nível que lhe permitiu escrever romances. Porém, apesar de desenvolver a linguagem escrita, o mesmo não ocorreu com a linguagem falada, uma vez que o vocabulário adquirido era estranho ao linguajar cotidiano (Yakushiji, 2006, p. 238).

Assim, surge como resultado de seus estudos o livro Muchi no Namida, o primeiro romance de Norio Nagayama - publicado pela editora Godo, em 1971, e posteriormente pelas editoras Kadokawa Bunkô e Kawade Shobo Shinsha -, que se torna um sucesso de vendas. Trata-se de uma coletânea de poesia e prosa, com temas variados e que demonstram principalmente a sua crença de que a ignorância e a pobreza são os maiores

\footnotetext{
8 São caracteres da língua japonesa adquiridos a partir de caracteres chineses, que são utilizados para escrever japonês junto com os silabários katakana e hiragana.

9 É um dos alfabetos silábicos da língua japonesa, usado para todas as palavras para as quais não exista kanji ou, caso exista, seja pouco empregada.
} 
motores para que pessoas cometam crimes. Também fazem parte da obra os poemas que ilustram o seu cotidiano no cárcere, memórias de infância, a criminalidade na sociedade, dentre outros temas. A obra se divide nos seguintes capítulos: 1) Havia uma pessoa que só pensava na morte; 2) As palavras e a água que se diferenciavam dentro de mim; 3) A ira, o ódio e o amor; 4) A canção do verme; 5) O lugar mais claro é o que se torna mais sombrio; 6) Para a vingança de vocês; 7) O pensador infantil; 8) O revolucionário solitário; 9) A fome deseja o desconhecido; 10) A aproximação ao ego. Essa obra tem como objetivo principal a busca da sua motivação para o cometimento dos crimes e nela adquire destaque a discussão sobre a responsabilidade penal. Apesar desse questionamento se voltar para os seus anos na infância, o autor não trata dos crimes cometidos:

Sou um prisioneiro que matou quatro pessoas. Acredito que não seja possível esquecer estes assassinatos, mas de qualquer forma, não quero tocar nesse assunto no livro. Este caderno se tornará inútil caso me lembre disso (Nagayama, 1990, p. 11).

Durante toda a sua vida literária, que durou quase três décadas, Nagayama se refere superficialmente aos assassinatos.

É como se a lembrança dos crimes cometidos dificultasse sua autoaceitação, o que o faz manter o posicionamento do "não quero tocar", "não quero lembrar" desse assunto (Hosomi, 2010, p. 153); porém, quando o tema emerge, surge na forma de uma autojustificativa que beira o esdrúxulo:

Eu matei pessoas. Se for pensar nisso agora, se devo dizer ou não, foi um modo especial de matar. As pessoas falam em perversidade e crueldade [...] mas, quando cometem suicídio, por exemplo, usando uma pistola, eles miram no cérebro. Eles querem uma morte rápida. Ao pensar em existência, tenho convicção que o meu modo de matar é um modelo de crueldade, entretanto, acredito que as pessoas intelectualizadas conseguem compreendê-lo. Se for resumir em poucas palavras, é o fato de ter matado de forma fácil. A morte deverá ser sem sofrimento (Nagayama, 1990, p. 240).

A comparação entre o suicídio e o homicídio não leva em consideração a autonomia do indivíduo, e Nagayama desconsidera o fato de que no suicídio a pessoa comete o ato contra a sua própria vida e não 
prejudica outros indivíduos ${ }^{10}$. Retirar a vida de alguém é a pior das atrocidades: curiosamente, Nagayama, nessa oportunidade, deixa de abordar a crueldade implicada no modo como será executado. Tal questão foi discutida pelo Supremo Tribunal Japonês ao examinar a aplicação de penas cruéis face ao que prevê o art. 36 da Constituição: “A imposição de tortura e punições cruéis por qualquer agente público são absolutamente proibidas”. Mas, a constitucionalidade da pena foi confirmada pela decisão da Suprema Corte Japonesa em 12 de março de 1948, a qual levou em consideração o modo de execução, e não a perda da vida. Segundo o entendimento da Corte, o enforcamento não é um modo cruel de execução, como o seriam a decapitação, a ferventação, a crucificação e outros métodos utilizados no passado.

\section{A interpretação da responsabilidade em Muchi no namida}

O momento da ocorrência do "ato criminoso" representa apenas um instante da vida de uma pessoa - no restante do tempo, ela é cidadã comum. Por quê? O que reflete o instante em que o crime foi cometido? Segundo Nagayama, o crime não é nada mais do que uma ação anormal ocorrida num instante e, portanto, julgar o criminoso baseando-se apenas nesse momento resulta na fomentação do preconceito. Entretanto, o instante acaba por refletir em todo o período restante, que não inclui o crime (Takeda, 2010, p. 54). Tal reflexão sobre o ato em si é rapidamente substituída pela sua busca profunda quanto às causas do cometimento de seus crimes. Nagayama questiona-se da seguinte forma:

Descobri. A minha própria ignorância e então essa descoberta se deve ao pouco estudo atual que fiz na prisão... Se for concluir em poucas palavras o porquê de ter me tornado assim, tudo, tudo, tudo, tudo se deve à minha vida miserável. Da pobreza nasce a ignorância (Nagayama, 1990, p. 230).

\footnotetext{
${ }^{10}$ A preocupação em prejudicar o próximo é comum na cultura japonesa e, dependendo da forma do suicídio, por exemplo, caso o indivíduo se jogue na frente do trem, caberá indenização da família do suicida à companhia de trem ou metrô, uma vez que a empresa e os usuários são prejudicados com a paralisação decorrente da morte.
} 
Nessa mesma linha, o autor se manifestou perante o juízo durante a $12^{\mathrm{a}}$ audiência do Tribunal Distrital de Tóquio, no dia 30 de junho de 1970:

Réu: Você sabe muito bem sobre a minha origem. Os fatos aconteceram porque naquela época, eu era ignorante. Era pobre e ignorante... Um homem como eu, só está aqui por ser pobre. Eu odeio isso. Eu cometi os crimes porque eu odeio.

Juiz: Quem você odeia?

Réu: Eu odeio qualquer coisa. Odeio todos! E seguiu falando em inglês: "Os pobres assassinam o sentimento social, destroem as relações entre as pessoas". A sociedade capitalista cria pobres e é por isso que estou aqui! (Otsuka, 1997, p. 82).

Todos ficaram surpresos com o fato de um jovem que tinha apenas o ensino fundamental poder se manifestar em inglês durante a audiência (Saki, 1994, p. 72). Nagayama tinha a forte crença de que era uma vítima das circunstâncias, que o meio social em que viveu impulsionou-o à marginalidade, alimentando-se de um determinismo radical. Se acreditássemos que as ações humanas são o resultado de circunstâncias, as pessoas não seriam realmente responsáveis pelo que fazem; podemos afirmar que as ações humanas são realmente influenciadas pela hereditariedade e por circunstâncias externas? Apesar do exaustivo trabalho de psicólogos, sociólogos e neurologistas, ainda há muito a ser descoberto nessa área (Onoré, 1998, p.181). Os excluídos da sociedade fazem esse tipo de interpretação porque, fundamentalmente, eles têm a sensação de não ter o controle das suas próprias vidas. Por isso, acreditam que, se a sociedade melhorasse, a criminalidade desapareceria. É provável que tal percepção esteja equivocada, uma vez que o importante é ter a sensação de que um mundo maior do que eu exista e de que pertencemos a ele (Iguchi, 1988, p. 79).

É verdade que o direito penal e a moralidade tratam os agentes como vítimas das circunstâncias, desde que impeçam a capacidade do agente de tomar uma decisão racional. Quando a pessoa tem sua capacidade reduzida e comete um crime, a debilidade é levada em consideração, ainda que não seja possível comprovar que o comportamento criminoso foi causado por essa deficiência. Nesse caso, a capacidade é levada em consideração pelo princípio da retribuição, pois a punição não deve ser desproporcional à culpa (Onoré, 1998, p. 184). 
Nagayama foi submetido a duas avaliações psiquiátricas para verificar se ele tinha alguma doença mental. O primeiro exame, realizado em 1971, atestou sanidade mental, portanto seria imputável juridicamente, resultado oposto da segunda avaliação, realizada entre 1973 e 1974, que apontou uma diminuição de sua capacidade mental. Apesar de o segundo exame ser muito mais detalhado e de ter sido realizado durante um período mais longo, o juiz escolheu descartá-lo, tendo em vista apresentar contradições com as declarações recolhidas durante a investigação dos crimes (Otani, 2010, p. 138). Assim, Nagayama foi considerado imputável e condenado à morte - contudo, na decisão da Suprema Corte de Tóquio, a qual faria a comutação à pena perpétua em 1981, o juiz reconheceu que o Estado deveria ter promovido políticas públicas para o bem-estar da população (Obara, 2013, p. 44). Entretanto, essa decisão foi revertida, e Nagayama acabou por ser executado.

Em sua obra, Nagayama lamenta-se de sua vida miserável e projeta hipóteses - construindo, poeticamente, uma cartografia da "sociedade ideal” - que tornariam possível eliminar a criminalidade ou, numa perspectiva mais real, diminuir sua ocorrência:

Não há pobres no socialismo

Todos ficam unidos quando a vida está difícil Quando a política está frágil todos dão ouvidos Ninguém foge deste grupo No Japão também esse dia chegará

E, então, o país se transformará e não haverá pessoas como eu

Pessoas!

Não façam o meu grito ser em vão

Eu caí no estado desumano, mas vocês ainda o são

Não façam o meu grito ser em vão

Ou ou

Vocês ainda deixarão surgir um segundo caso, como o meu?

Isso é triste, não é? (Nagayama, 1990, p. 69).

Nagayama, então, sonha com uma sociedade sem desigualdades socioeconômicas. Todo crime tem uma causa, motivação e resultado. A causa ocorre no modo como cada indivíduo estabelece sua relação social e humana com a sociedade. A motivação surge das condições peculiares que o indivíduo possui nas relações sociais que o impulsionam para o crime. $\mathrm{O}$ resultado é o crime como fenômeno social e universal (Takeda, 2010, p. 6o). Nagayama acredita que o crime deveria ser avaliado de acordo com 
todos esses fatores; na aplicação da lei, o processo penal concentra-se apenas na motivação e no resultado. Além disso, o escritor afirma que, se apenas a motivação for levada em consideração - como, por exemplo, a cobiça pelo dinheiro, ódio etc. -, os crimes continuarão a se repetir: o crime nasceria da conjuntura de inadequação do lar, da educação pública e da sociedade.

A pena de morte, no entanto, não serve para julgar a situação da sociedade. Ela enfatiza que o condenado é o responsável pelas ameaças à sociedade, que os familiares da vítima merecem ser vingados, que a eliminação do algoz irá deixar a sociedade mais segura, comprovando, assim, a ineficácia das penas educacionais.

\section{CONCLUSÃO}

Nagayama foi um símbolo de luta para os abolicionistas da pena de morte no Japão. Após entrar no cárcere, passou o seu tempo estudando e escrevendo, tendo doado os lucros da vendagem dos livros para as famílias das vítimas. Demonstrou arrependimento dos seus crimes durante a vida, mas essa mudança não foi convincente para livrá-lo da sua execução. Se essa mudança drástica ocorrida em quase três décadas no cárcere não foi suficiente para mantê-lo vivo, seria possível argumentar que o sistema penal japonês prioriza a eliminação dos elementos indesejáveis da sociedade e o espírito de vingança dos familiares das vítimas. Não se fundamenta na ressocialização e regeneração do condenado, princípio adotado em grande parte dos países na atualidade.

O desenvolvimento da sua linguagem ocorreu de maneira inversa ao de pessoas comuns, uma vez que dominou inicialmente a linguagem escrita para depois ter desenvolvida a habilidade de expressar-se oralmente. Não seria exagero afirmar que a sua escrita pôde nascer exatamente a partir de sua condição. Paradoxalmente, enquanto Nagayama evita tocar nas lembranças traumáticas dos instantes em que cometeu o crime, a sua existência como escritor só nasceu por conta do cárcere. Na reclusão, pela primeira vez, teve de enfrentar os traumas vividos na juventude e a inaptidão em transmitir seus sentimentos fazendo uso de expressões plausíveis e que favorecem a boa comunicação. Procurou fugir da sua 
realidade na prisão através da atividade criativa e escolheu uma vida de superação ao invés de uma espera inerte pela sua execução.

\section{REFERÊNCIAS}

CHANG, Li-Ching. The Research Comparison between Law and Literature: As illustrated by Kafka's "The Trial", National Taiwan University Law Review, Taiwan, v. 3, n. 1, p. 69-88, 2008.

DANDO, Shigemitsu. Toward the Abolition of Death Penalty, Indiana Law Journal, Bloomington, v. 72, n. 7, p. 7-19, 1996.

GEIS, Gilbert. Pioneers in Criminology VII--Jeremy Bentham (1748-1832), Journal of Criminal Law, Criminology \& Police Science, v. 46, p. 159-171, $1955^{-1956 . ~}$

GODOY, Arnaldo Moraes. Direito e literatura. Revista de Estudos Judiciários, n. 22, p. 133-136, 2003.

HOSOMI, Kazuyuki. Nagayama Norio-aruhyogenno shimei (Norio Nagayama- O Imperativo de uma expressão), Tóquio: Kawadebukkusu, 2010. 213p.

IGUCHI, Toshio. Sakka no tanjyô. Nagayama Norio ron (O nascimento de um escritor- a teoria sobre Norio Nagayama), Waseda Bungaku, v. 141, n. 8, p. 74-90, 1988.

INTERNATIONAL FEDERATION FOR HUMAN RIGHTS, THE 2003 Death penalty in Japan: a practice unworthy of democracy. Disponível em: <http://www.fidh.org/IMG/pdf/jp359a.pdf>. Acesso em: 15 set. 2015.

ISHIKAWA, Machiko. Writing the sense of the loss in the inner self: a narrative of Nakagami Kenji and Nagayama Norio in Late 1960s. In: $18^{\text {th }}$ BIENNIAL CONFERENCE OF THE JAPANESE STUDIES ASSOCIATION OF AUSTRALIA, Sidney, 2013. Anais... Sidney. Disponível em: <http://japaninstitute.anu.edu.au/sites/default/files/u6/o5_Machiko_IS HIKAWA-JSAA2013.pdf>. Acesso em: 21 mar. 2015.

MÉTRAUX, Daniel A. The Nagayama criteria for assessing the death penalty in Japan: reflections of a case suspect. Southeast Review of Asian Studies, v. 31, p. 282-289, 2009.

NAGAE, Neide Hissae. De katai a dazai: apontamentos para uma morfologia do romance do eu. Tese (Doutorado em Literatura)Universidade de São Paulo, São Paulo, 2006. 233 f.

NAGAYAMA, Norio. Muchi no namida. Tóquio: Kawadebunko, 1990. 540p.

NEW YORK TIMES, THE. In Secrecy, Japan Hangs a Best-Selling Author, a Killer of 4, Disponível em: <http://www.nytimes.com/1997/o8/o7/world/ in-secrecy-japan-hangs-a-best-selling-author-a-killer-of-4.html>.Acesso em 15 out. 2015 .

OBARA, Mika. Government justification for capital punishment in Japan: case study of de facto moratorium period from 1989 to 1993. Doctoral thesis. Loughborough University, Loughborough, 2013. $322 \mathrm{f}$. 
ONORÉ, Tony. Being Responsible and Being a Victim of Circumstance. In: PROCEEDINGS OF THE BRITISH ACADEMY, Maccabaean Lecture in Jurisprudence, London: British Academy, 1998. p. 169- 187.

OTANI, Kyoko. Soredemokarewoshikeinishimasuka?Abashirikara Peruhe-harukanaru tabi. (Mesmo assim o condenam à morte? De Abashiri ao Peru-a última viagem). Tóquio: Gendaikikakushitsu, 2010. 229 p.

OTSUKA, Eiji. Saigono kyoyoshosetsu (O último romance compartilhado). Chuokoron, Tóquio, v. 11, n.112, p.74-85, 1997.

POSNER, Richard A. Law and literature: a relation reargued, Virginia Law Review, v. 72, n, 8, p. 1351-1392, 1986.

POTTER, Nelson T. The principle of punishment is a categorical imperative, Faculty Publications University of Nebraska-Department of Philosophy, paper 22, p. 169-190, 1998.

SAKI, Ryuzo. Shikeishu Nagayama Norio (Norio Nagayama-O condenado à morte). Tóquio: Kodansha, 1994. 473p.

SATO, Mai. Public attitudes to the death penalty in Japan. In: LEHRFREUND, Saul; JABBAR, Parvais (Eds.). The Death Penalty in Japan. London: The Death Penalty Project; Centre for Prisioner's Right, 2013. p. 31-53. Disponível em: <http://www.deathpenaltyproject.org/wpcontent/uploads/2013/03/DPP-Japan-report.pdf>. Acesso em: 15 out. 2015 .

SINNOT-ARMSTRONG, Walter. Consequentialism. In: ZALTA, Edward N. (Ed.). The Stanford Encyclopedia of Philosophy (Winter 2015 Edition). Disponível em: <http://plato.stanford.edu/archives/win2015/entries/con sequentialism/>. Acesso em: 15 out. 2015.

TAKEDA, Kazuo. Shishaha mata tatakau - Nagayama Norio saibanno shinsoto shikeiseido (Norio Nagayama - O morto ainda luta; o julgamento e a verdade sobre a pena de Morte). Tóquio: Meisekishoten, 2010. 266p.

TAMAGNONE, Diego e OLIVEIRA, Rejane Pivetta. A igualdade da lei e a diferença da literatura: a narrativa marginal de Ferréz. Revista Língua e Literatura, v. 15, n. 24, p.31-47, 2013.

TRINDADE, André Karam. Kafka e os paradoxos do direito: da ficção à realidade. Diálogos do Direito, v.2, n.2, 2012. Disponível em: <http://ojs.ce suca.edu.br/index.php/dialogosdodireito/article/view/63/76>. Acesso em: 10 out. 2015 .

YAKUSHIJI, Koji. Nagayama Norio kikoenakkata kotoba (As palavras que Norio Nagayama não conseguiu escutar), Tóquio: Nihon Hyoronsha, 2006. 257p.

Idioma original: Português

Recebido: 29/11/15

Aceito: 30/01/16 